\title{
A QFD-based decision making model for computer-aided design software selection
}

\author{
Kanika Prasad $^{\mathrm{a}}$ and Shankar Chakraborty ${ }^{\mathrm{b}^{*}}$
}

${ }^{a}$ Department of Production Engineering, Jadavpur University, Kolkata - 700 032, India

${ }^{b}$ Department of Production Engineering, Jadavpur University, Kolkata - 700 032, India

CH R O N I C LE

Article history:

Received October 28, 2015

Received in revised format

November 28, 2015

Accepted January 17, 2016

Available online

January 20, 2016

Keywords:

Decision making

Selection

QFD technique

CAD software

\begin{abstract}
A B S T R A C T
With the progress in technology and innovation in product development, the contribution of computer- aided design (CAD) software in the design and manufacture of parts/products is growing on significantly. Selection of an appropriate CAD software is not a trifling task as it involves analyzing the appositeness of the available software packages to the unique requirements of the organization. Existence of a large number of CAD software vendors, presence of discordance among different hardware and software systems, and dearth of technical knowledge and experience of the decision makers further complicate the selection procedure. Moreover, there are very few published research papers related to CAD software selection, and majority of them have either employed criteria weights computed utilizing subjective judgements of the end users or floundered to incorporate the voice of customers in the decision making process. Quality function deployment (QFD) is a well-known technique for determining the relative importance of customers' defined criteria for selection of any product or service. Therefore, this paper deals with design and development of a QFD-based decision making model in Visual BASIC 6.0 for selection of CAD software for manufacturing organizations. In order to demonstrate the applicability and potentiality of the developed model in the form of a software prototype, two illustrative examples are also provided.
\end{abstract}

\section{Introduction}

Design of various components/parts is an extensively practiced industrial/manufacturing art in architectural design, prosthetics, numerous applications of automotive, shipbuilding and aerospace industries. Integration of this art with computer system not only facilitates reproduction of longer manual drafting process into shorter electronic drafting procedure, but also provides an opportunity for significant productivity enhancement. Computer-aided design (CAD), also termed as mechanical design automation, has been widely used in manufacturing industries to create technical drawings through the application of computer software with a view to help organizations in achieving high speed production. CAD software is used to increase productivity of the designer, enhance quality of design, improve communications through documentation and create a database for manufacturing. Moreover,

* Corresponding author

E-mail address: s_chakraborty00@yahoo.co.in (S. Chakraborty) 
its implementation in a manufacturing organization would minimize design error and improve performance in an economical way through better optimization of the design parameters. There exists an assortment of CAD software packages with numerous features in the market. These features range from $2 \mathrm{D}$ vector-based drafting systems to $3 \mathrm{D}$ solid and surface modelers. Furthermore, many modern CAD software packages now offer advanced animation and rendering capabilities, which allow rotations in all the three dimensions, thus facilitating visualization of the desired view of a designed object from different angles. While utilizing these software packages, engineers are also able to look into the inside of a product that helps them to envisage their design in a superior way. But with the increase in number of features in CAD software, its overall purchasing cost also escalates. Occasionally, some of the advanced features may not even be required by the concerned organization. It is also acknowledged that any single CAD software package available in the market is incapable to entirely satisfy all the requirements and expectations of an organization, because each organization operates its own business with different strategies and objectives. Thus, managers of the organization must choose a particular CAD software package which meets their needs most closely. Moreover, selection of an unsuitable CAD software may adversely affect the designing process of a product which in turn, hinders the long term functionality and sustainability of the organization. Therefore, choosing an appropriate CAD software is a complicated and crucial task as it involves minute and careful analysis of multiple conflicting criteria affecting the decision making process.

It is observed that due to varying complex features of CAD software and abundance of alternatives, a methodical procedure for their selection is formidable and expensive. Scarcity of time and lack of expertise to make superior decisions about CAD software packages can further make the selection procedure a daunting task. In addition, choosing an appropriate CAD software plays a critical role to ensure better quality of products, minimize production costs, downsize lead times and enhance the general productivity of the manufacturing organizations. So, managers of the organization repeatedly face the difficulty of evaluating a wide range of CAD software options and choosing the best one based on a set of conflicting criteria. This generates a need for development of a logical and systematic approach to aid the management of the organization in identifying the best suited CAD software for its specific function, which would be able to match the customers' needs with technical requirements for the intended function. Quality function deployment (QFD) is a comprehensive quality tool particularly aimed at satisfying customers' requirements (Şen \& Baraçl1, 2010). This paper proposes a model on the basis of QFD technique to guide the decision makers in choosing the most suitable CAD software. In order to ease out the entire CAD selection process, a user friendly software prototype in Visual BASIC 6.0 is also developed.

\section{Literature review}

Liberatore and Pollack-Johnson (2003) analyzed and assessed various factors influencing the extent of usage, type of usage and selection of project management software by the professional experts. Cochran and Chen (2005) developed a fuzzy set approach for multi-criteria selection of object-oriented simulation software for analysis of a production system. Mulebeke and Zheng (2006) presented a methodology for assisting selection of a suitable software to suit the development process of a particular product. Ayă̆ and Özdemİr (2007) applied a fuzzy analytic network process (ANP)-based methodology for enterprise resource planning (ERP) software selection while considering both quantitative and qualitative objectives. Kannan and Vinay (2008) evaluated CAD/computer-aided manufacturing (CAM) systems based on product literature. Perera and Costa (2008) developed a multicriteria decision model using analytic hierarchy process (AHP) for selection of ERP systems for manufacturing organizations. Jadhav and Sonar (2009) provided an overview on the literature associated with evaluation and selection of software packages. Karaarslan and Gundogar (2009) emphasized on the appropriateness of ERP modules to the production type and process rather than basic software selection criteria (cost, implementation time, functionality, user friendliness etc.) for ERP evaluation. Rao and Rajesh (2009) presented an effective decision making framework for software 
selection in manufacturing industries using preference ranking organization method for enrichment evaluations (PROMETHEE). Şen et al. (2009) adopted an integrated decision support system to assist decision makers in enterprise software selection process while considering both qualitative and quantitative objectives in a multi-objective mathematical programming model. Yazgan et al. (2009) developed a new model combining ANP method and artificial neural network for ERP software selection. Azadeh et al. (2010) presented a robust decision making methodology based on fuzzy AHP method for evaluating and selecting an appropriate simulation software package. Şen and Baraçlı (2010) developed a fuzzy QFD approach for determining the non-functional requirements important to an organization's software selection decision in accordance with its functional needs. Hou (2010) presented an approach for suitable software selection with triangular fuzzy linguistic variables based on fuzzy linguistic weighted harmonic mean operators. Zakria et al. (2010) employed AHP method as a decision making tool for identifying and prioritizing important factors for CAD/CAM software selection. Jadhav and Sonar (2011) proposed a hybrid knowledge-based system to help decision makers in evaluation and selection of software packages. Misra and Ray (2012) developed a sensitivity analysis model to aid the decision makers to choose efficient software packages.

It can be summarized from the review of the past researches that only a few knowledge-based systems have been designed and developed for solving CAD software selection problems, but those systems have mainly estimated criteria weights employing subjective perception of the managers/decision makers. Besides, they have miserably failed to recognize the importance of the customers' requirements, which is the fundamental encouraging factor for any organization to forge ahead in this global competitive market. It is well acknowledged that implementation of a CAD software package in any manufacturing organization involves significant cost in terms of its license cost, installation cost, maintenance cost and hardware cost, which can easily offset the benefits extracted from the superior designing capabilities of the installed software. Thus, selection of the most suitable CAD software from a pool of alternatives is a critical decision making problem for justification and implementation of the same for performing the given functions. So, in this paper, a database is first created that includes all the information relevant to different technical specifications of various available CAD software packages typically employed in the manufacturing domain. It is then integrated with a decision guidance framework to help the decision makers in selecting the most appropriate CAD software for a given set of requirements. Additionally, this designed QFD-based decision making model can be periodically upgraded in order to resolve the dynamic nature of the decision making problem.

\section{Development of a QFD-based decision-making model for CAD software selection}

\subsection{QFD methodology}

Consumer's wish, readiness and capability to pay the cost for a particular commodity or service are best described by the economic theory of demand. In this cut-throat contemporary market environment, customers are the main emphasis for many organizations with a view to achieve competitive edge. All the strategic, tactical and operational decisions are driven by consumers' wants and needs. No strategy is implemented until it satisfies the assessment of consumer research. Furthermore, there was a time when quality of product was a competing and luxury item for an organization, but in today's dynamic market, it has transformed into a basic necessity. At the same time, the focus of the organizations has been more and more accentuated on methodologies and techniques for sustaining design and development of products which satisfy the specifications defined by the customers. The QFD technique is visual representation of a well thought-out engineering procedure, and an array of interrelated engineering and management tools, which can institute precedence of the customers by means of their voice and convert them to design characteristics during development of a product. It basically prioritizes and relates the product development procedure to assure quality of a product as defined by the customers. The QFD technique also considers choices and preferences of a group of populace representing different functional departments that are associated in product development, like 
marketing, design, quality assurance, manufacturing/sales, testing, finance, product support etc. The capability to process both qualitative and quantitative data, and to serve as a pliable framework which can be abridged, extended and integrated with other quality design and improvement methodologies is the major advantage elicited from the application of QFD technique in an organization.

The QFD tool was developed in late 1960s in Japan by Akao who is regarded as the father of QFD and was initially applied at the Mitsubishi Heavy Industries Kobe Shipyard in 1972 under the guidance of Shigeru Mizuno and Yasushi Furukawa (Akao, 1990). The documentation of the pertinent information and preferences about a product is carried out through a house of quality (HOQ) matrix in this technique, as shown in Fig. 1. The HOQ matrix is the heart of QFD technique, and it represents the relationships between customers' needs and technical requirements for the considered product. Even though, these relationships depict the opinion of the quality subject matter specialists, encompassing preference of other analysts during the assessment process would considerably minimize prejudice in the evaluation. The HOQ matrix underlines the strongest relationships so that they can be prioritized and tackled independently. It comprises of six key building blocks presented as below:

a) Customers' needs - It includes a set of customers' desires, expectations and requirements from the product.

b) Technical requirements - It consists of a list of technical descriptors that explains about how the customers' needs can be fulfilled.

c) Interrelationship matrix - It is the interior of the house, and explicates the relationship between customers' requirements and design characteristics using symbols or numbers.

d) Technical correlation matrix - It is also termed as roof of the matrix and demonstrates how each of the technical requirements influences each other.

e) Planning matrix - It encompasses the quantified customers' needs and positions them in order of their importance.

f) Prioritized technical requirements - Here, technical requirements are evaluated to decide their relative significance and are ranked accordingly.

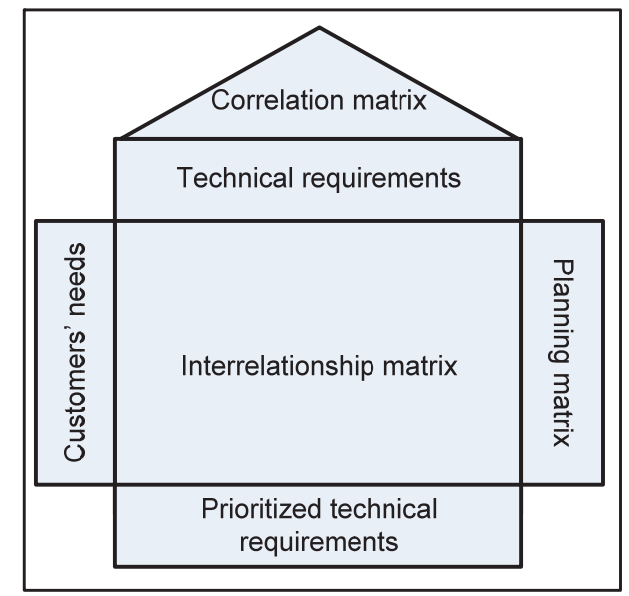

Fig. 1. HOQ matrix

\subsection{QFD-based model for CAD software selection}

CAD has been possibly one of the most exceptional inventions in engineering field in the last few decades. It has revolutionized the way engineers accomplish practically all aspects of their daily business. CAD software provides automated drafting, analysis and design capabilities to any manufacturing organization. Today in this highly competitive and demanding market, it is impossible for an engineering enterprise to sustain itself devoid of taking advantage of the prowess and competency which CAD software offers. This paper presents a QFD-based decision making model for selecting 
CAD software packages on the basis of a particular set of functional requirements of the end user. The developed system provides a set of feasible CAD software alternatives for the given application from an exhaustive list of options available in the market and subsequently generates their ranking preorder. The selection and assessment of software package in this system is carried out in a consistent and quantifiable way in order to make the decision making process more effective and accurate. It is well acknowledged that change in many factors, like operating platform, hardware capacity, processor capability etc. significantly influences the efficiency and productivity of CAD software. Therefore, the managers of a manufacturing organization need to have a clear understanding about this selection problem. The QFD-based decision making model is made completely automated through development of a software prototype which is integrated with a database of CAD software alternatives with a view to minimize human intervention. Visual BASIC 6.0 is employed here to develop this software prototype owing to its user friendly graphical interface. The framework of the developed QFD-based software prototype for CAD software selection is exhibited in Fig. 2. The major steps involved in development of this system are described in details here-in under.

An exhaustive database of various CAD software alternatives available in the market with their technical specifications is developed in the first step. The catalogs and brochures of different CAD software developers present on their corresponding websites are referred here to accumulate the relevant information and detailed data related to the capabilities of various CAD software options. Next, past research works, published books and periodicals are consulted in order to identify various important technical criteria based on which CAD software alternatives would be evaluated. Different crucial technical specifications associated with CAD software selection are enlisted as below:

a) Capability - It represents the ability to execute a particular set of functions, like creating $2 \mathrm{D}$ and 3D models with a variety of other modeling and design features, performing simulation and analysis, estimating cost, documentation etc.

b) Disk space (in GB) - It signifies the minimum disk space requirement to install and run a particular CAD package.

c) Hardware requirements - They are needed to utilize a CAD software efficiently. If a computer system does not satisfy the minimum hardware requirements, the CAD software may not operate satisfactorily after installation. Some of the examples of hardware requirements are optimal processor speed, correct graphics device etc.

d) Language support - It denotes the number of languages supported by a CAD software for its easy implementation and utilization.

e) License cost (in USD) - It is the cost paid by the end user to use one or more copies of the software devoid of violating copyrights for a given period of time. Software licenses usually are either proprietary or open source.

f) Maintainability - It is the effortlessness with which CAD software can be modified to correct mistakes, enhance performance or other characteristics, or adjust to a transformed environment.

g) Portability - It indicates the ability of a CAD software to function appropriately on different operating systems with no or slight modification.

h) Readable files - It specifies the number of file formats that a CAD software can read.

i) Usability - It signifies the easiness with which a CAD software can be employed to achieve the desired goals effectively and efficiently by different end users. Usability evaluates the extent of complexity associated with utilizing a user interface.

j) Upgradability - It denotes the competency of a CAD software to upgrade itself into newer version with minimum monetary outlay.

k) Writable files - It provides details about the number of file formats in which 2D and 3D design data and metadata can be stored while utilizing a particular CAD software. 


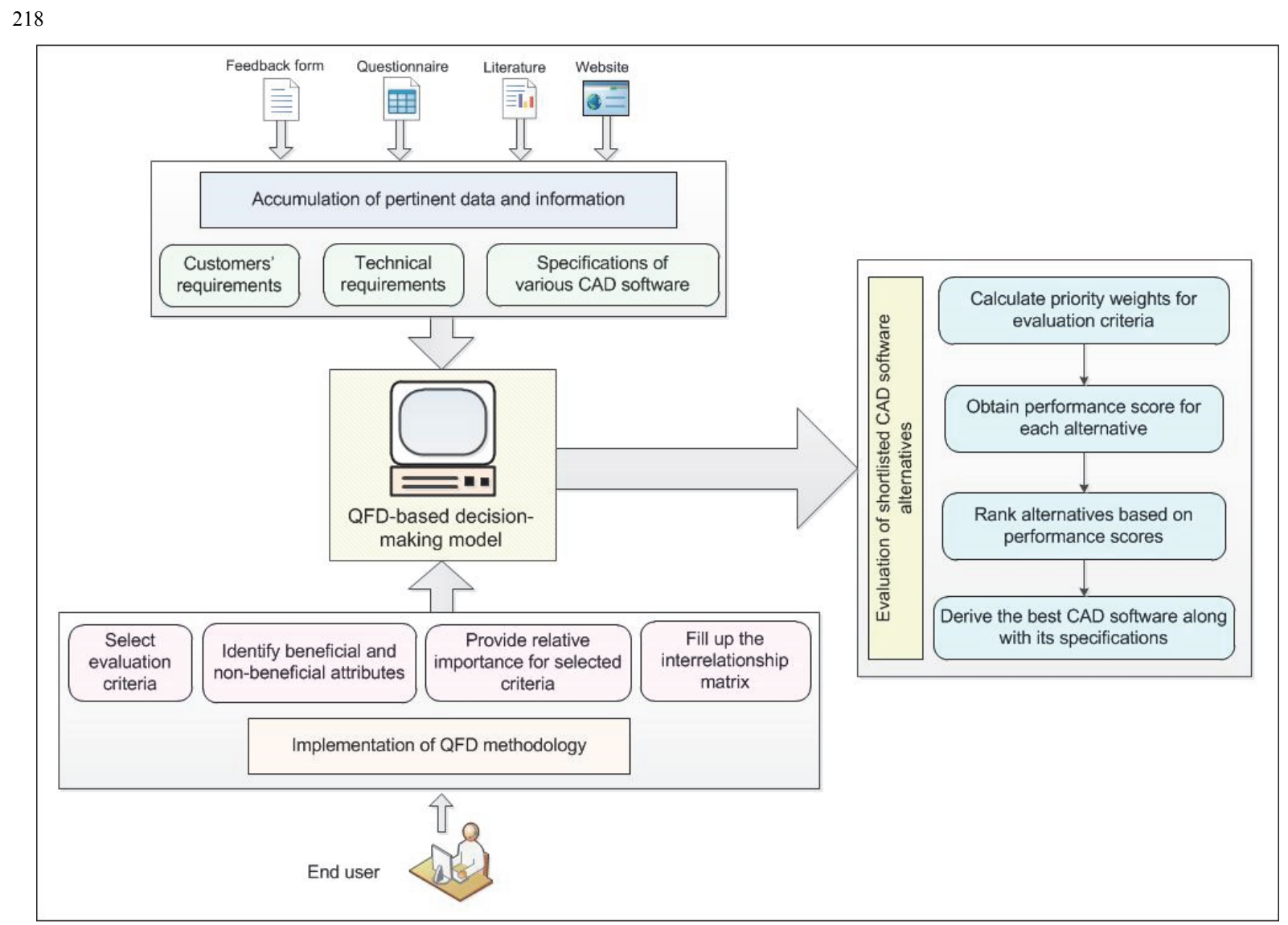

Fig. 2. Framework for QFD-based model for CAD software selection

Amongst all these technical specifications, capability, hardware requirements, maintainability, portability, usability and upgradability are expressed using a relative scale of 1-5, where 1 and 5 represent the lowest and the highest values respectively, as given in Table 1.

Table 1

Scale representing relative values for specifications of CAD software

\begin{tabular}{cc}
\hline Scale & Interpretation \\
\hline 1 & Lowest \\
2 & Low \\
3 & Moderate \\
4 & High \\
5 & Highest \\
\hline
\end{tabular}

Subsequently, based on a market survey employing questionnaires and customers' feedback forms, the demands of the customers related to selection of CAD software are shortlisted. The important customers' requirements related to choosing CAD software are recognized as shortcuts and one click options, inbuilt features, graphical interface, instruction manuals or tutorials, convertibility to different file formats, language support, output to printers or plotters, purchasing cost, installation and implementation cost, user friendliness, ability to run on different operating platforms, storage needed in the form of disk space, upgradation of the software and handling errors or troubleshooting.

The next stage involves in the implementation of QFD methodology. It begins with the selection of technical requirements or specifications on the basis of which the CAD software alternatives need to be evaluated. Then, the beneficial or non-beneficial customers' requirements are identified. These customers' requirements are attributed by the value of the corresponding improvement driver $(+1$ for 
beneficial criterion and -1 for non-beneficial criterion). The interrelationship between customers' requirements and technical requirements, and priority weights assigned to the customers' requirements are documented using an appropriate scale of 1-9, as shown in Table 2. The HOQ matrix adopted here is a simplified one where technical correlation and planning matrices are not considered. The customers' requirements are positioned along the rows of HOQ matrix, whereas, technical requirements are placed at the top of HOQ matrix along its column.

Table 2

Scale indicating priority weight and correlation index

\begin{tabular}{ccc}
\hline Scale & Priority weight & Correlation index \\
\hline 1 & Not important & Very very weak relation \\
2 & Least important & Very weak relation \\
3 & Very less important & Weaker relation \\
4 & Less important & Weak relation \\
5 & Moderately important & Moderate relation \\
6 & Important & Strong relation \\
7 & Very important & Stronger relation \\
8 & Very very important & Very strong relation \\
9 & Most important & Very very strong relation \\
\hline
\end{tabular}

The 'Weight' functional key is then pressed to extract the priority weight of each of the selected technical requirements after the HOQ matrix is filled up with all the pertinent data, employing the following equation:

$$
w_{j}=\sum_{i=1}^{n} P r_{i} \times I D_{i} \times \text { Correlation index }
$$

where $w_{j}$ is the weight for $j^{\text {th }}$ technical requirement, $n$ is the number of customers' requirements, $I D_{i}$ is the value of improvement driver for $i^{\text {th }}$ customer requirement, $P r_{i}$ is the priority assigned to $i^{\text {th }}$ customer requirement and correlation index is the relative importance of $j^{\text {th }}$ technical requirement with respect to $i^{\text {th }}$ customer requirement.

The final stage of the QFD-based decision making model consists of shortlisting the CAD software alternatives that need to be evaluated based on the set criteria. A decision matrix consisting of the selected technical specifications with respect to each chosen CAD software option is developed while extracting the corresponding information from the database. Furthermore, a linear normalization technique is employed here to make the decision matrix dimensionless so that the performance of all the alternatives can be compared with respect to the set criteria. The performance score for each CAD software is now estimated using the following expression:

$$
\text { Performance score }\left(\mathrm{PS}_{i}\right)=\sum_{j=1}^{n} w_{j} \times(\text { Normalized value })_{i j}(i=1,2, \ldots, m ; j=1,2, \ldots, n)
$$

where $w_{j}$ is the weight for $j^{t h}$ technical requirement, $m$ is the number of alternatives and $n$ is the number of technical requirements. The weights for the technical requirements are automatically retrieved from the HOQ matrix. The selected CAD software alternatives are finally ranked and the most suitable choice for the given functional requirements is identified along with its detailed technical specifications.

\section{Illustrative examples}

Two examples are considered here to exhibit the applicability and potentiality of the developed QFDbased decision making model in solving CAD software selection problems. 


\subsection{Example 1}

This problem is intended towards identifying the most appropriate CAD software from an expedient list of alternatives, which can create, analyze, view and leverage product designs downstream employing parametric modeling. The desired characteristics that the chosen CAD software should have are a) superior competency, b) lower installation space requirement, c) minimal hardware requirements, d) economical procurement and e) higher maintainability.

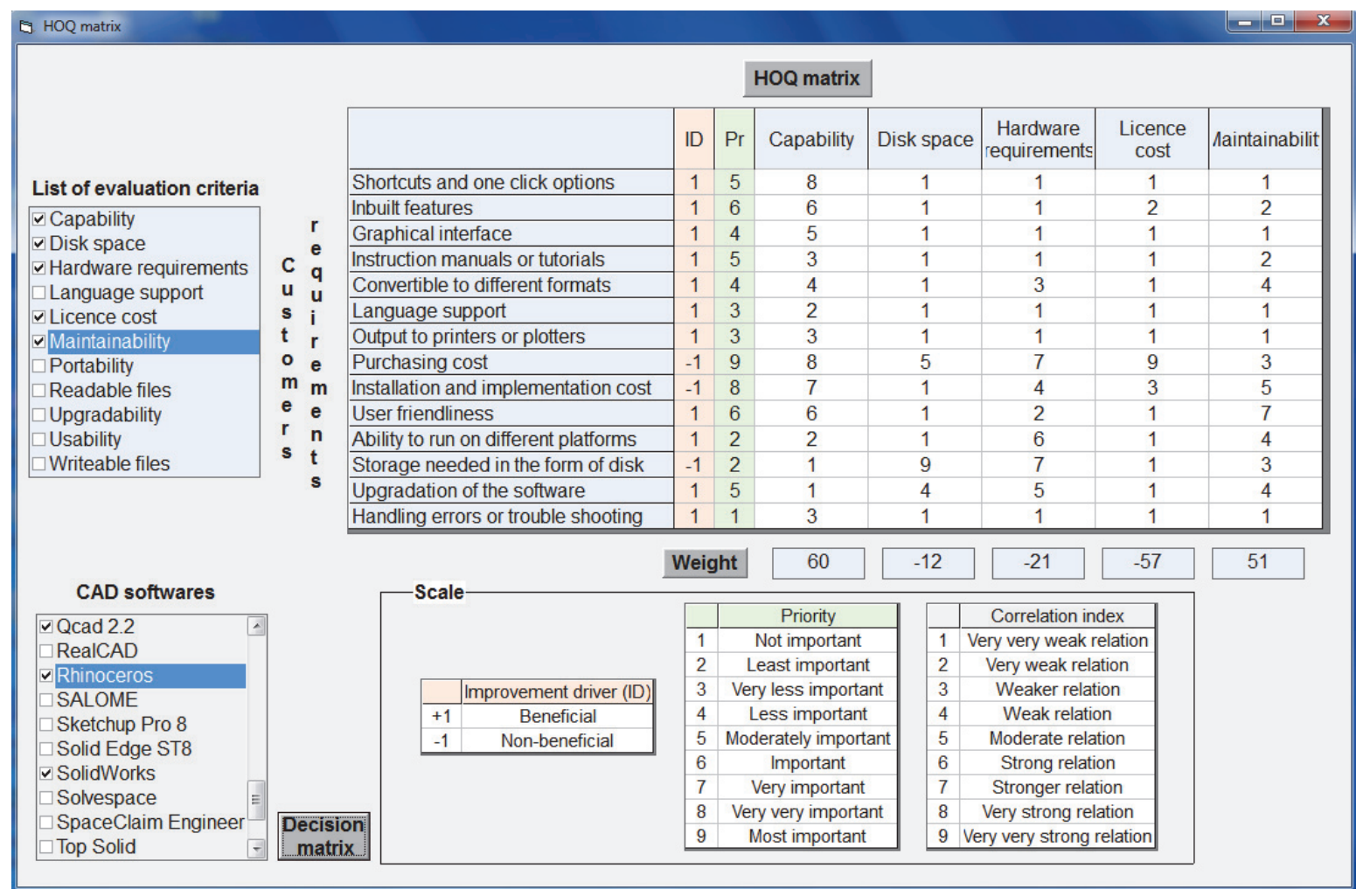

Fig. 3. HOQ matrix for Example 1

The end user first selects the desired CAD software attributes from 'List of evaluation criteria' module, as shown in Fig. 3. Different important evaluation criteria corresponding to the above-mentioned requirements are recognized as capability, disk space, hardware requirements, license cost and maintainability. Next, an empty HOQ matrix is automatically generated on pressing 'HOQ matrix' functional key. The improvement driver value for each customer's requirement is then entered into its respective position. The improvement driver values of +1 for 'Shortcuts and one click options', 'Inbuilt features', 'Graphical interface', 'Instruction manuals or tutorials', 'Convertible to different formats', 'Language support', 'Output to printers or plotters', 'User friendliness', 'Ability to run on different platforms', 'Upgradation of the software' and 'Handling errors or troubleshooting' signify that they are beneficial attributes requiring higher values. On the other hand, 'Purchasing cost', 'Installation and implementation cost' and 'Storage needed in the form of disk space' are assigned with improvement driver values of -1 representing their non-beneficial nature, preferred with lower values. The priority values for the customer's requirements are also entered into their respective cells. Subsequently, the relationships between customers' requirements and technical requirements demonstrated by the correlation indices are put into the HOQ matrix. The 'Weight' functional key is clicked to extract the priority weights for all the considered evaluation criteria after the HOQ matrix is properly filled up. It is noticed that disk space, hardware requirements and license cost have negative priority weights, whereas, capability and maintainability have positive priority weights. Along with pressing of 'Weight' functional key, a list of feasible CAD software packages fulfilling the set evaluation criteria is also 
available in the window. From that list, a set of eight alternatives is again chosen for final selection of the best CAD software package.

Pressing of 'Decision matrix' functional key generates the decision matrix for this CAD software selection problem in a new window while extracting the relevant information from the database. Figure 4 shows the performance scores and ranking preorder of the eight shortlisted CAD software alternatives. Pro/ENGINNER Wildfire 5.0 is identified as the most suitable CAD software for designing, analysis and manufacturing functions based on the considered criteria, followed by CATIA while applying this QFD-based model. Pro/ENGINEER can generate process plans with imbedded intelligence and is easy to use, while at the same time, is authoritative enough to fillet, round and shell even the most intricate geometry. Its cascading menus run in an insightful way, offering logical options and pre-selecting most frequent choices, besides short menu descriptions and full on-line help. It can operate on all of the major platforms, retaining the same look and feel on each system. These factors correctly validate the selection of Pro/ENGINEER as the best CAD software. Moreover, it can be observed that SolidWorks performs considerably well on most of the selected evaluation criteria, but its higher cost overshadows its all other benefits.

\begin{tabular}{|c|c|c|c|c|c|c|c|c|c|}
\hline \multicolumn{10}{|l|}{ Decision matrix } \\
\hline \multirow{2}{*}{\multicolumn{8}{|c|}{ Decision matrix }} & \multicolumn{2}{|c|}{ Specifications } \\
\hline & & & & & & & & $\begin{array}{l}\text { CAD software : } \\
\text { Developer : }\end{array}$ & $\begin{array}{l}\text { Pro/ENGINEER Wildfire } 5.0 \\
\text { PTC Inc., USA }\end{array}$ \\
\hline & $\mathrm{C} 1$ & $\mathrm{C} 2$ & $\mathrm{C} 3$ & C4 & C5 & Score & Rank & $\begin{array}{l}\text { Processor: } \\
\text { Disk space : }\end{array}$ & $\begin{array}{l}\text { Pentium } \circledast 4 \text { and above, } 2.4 \mathrm{GHz} \\
2.5 \mathrm{~GB}\end{array}$ \\
\hline AllyCAD Software & 4 & 0.234 & 3 & 1433 & 5 & 150.05 & 3 & RAM : & $1 \mathrm{~GB}$ \\
\hline BricsCAD & 4 & 1 & 2 & 740 & 2 & 125.13 & 4 & Readable files : & 6 \\
\hline CATIA & 5 & 4 & 2 & 1500 & 4 & 152.33 & 2 & Writeable files : & 15 \\
\hline DraftSight & 3 & 1 & 4 & 318.72 & 1 & 87.94 & 7 & Language support: & en, de, zh, fr, ja, it, es, ko, ru \\
\hline Pro/ENGINEER Wildfire & 5 & 2.5 & 2 & 1500 & 4 & 156.02 & 1 & Procurement cost : & 1500 USD \\
\hline Qcad 2.2 & 2 & 0.1172 & 1 & 30.61 & 1 & 90 & 5 & Installation : & Available \\
\hline Rhinoceros & 2 & 0.6 & 5 & 995 & 2 & 66.7 & 8 & Training: & Available \\
\hline SolidWorks & 5 & 5 & 2 & 3995 & 2 & 88.5 & 6 & Maintenance : & Easy \\
\hline & & & & & & & & $\begin{array}{l}\text { Upgradation: } \\
\text { Features : }\end{array}$ & $\begin{array}{l}\text { Capable } \\
\text { Parametric modelling } \\
\text { Assembly management }\end{array}$ \\
\hline
\end{tabular}

Fig. 4. Decision matrix for Example 1

\subsection{Example 2}

In this example, an appropriate CAD software for generating several types of drawing views and formats, including general, projection, auxiliary, detailed, exploded, partial, area cross-section and perspective needs to be selected from a wide range of available alternatives. Therefore, 'Language support', 'Portability', 'Readable files' and 'Writable files' are chosen as the evaluation criteria on the basis of which CAD software packages need to be evaluated. The designed model generates an empty HOQ matrix that is consequently filled up by the end user with relevant information. The corresponding HOQ matrix is depicted in Fig. 5 where the priority weights for various evaluation criteria for this CAD software selection problem are shown as already been estimated. The positive priority weights for all the four criteria, i.e. language support, portability, readable files and writable files indicate that their higher values are always preferred. Next, the end user chooses a set of ten feasible CAD software alternatives for ultimate selection of the most suitable one. 


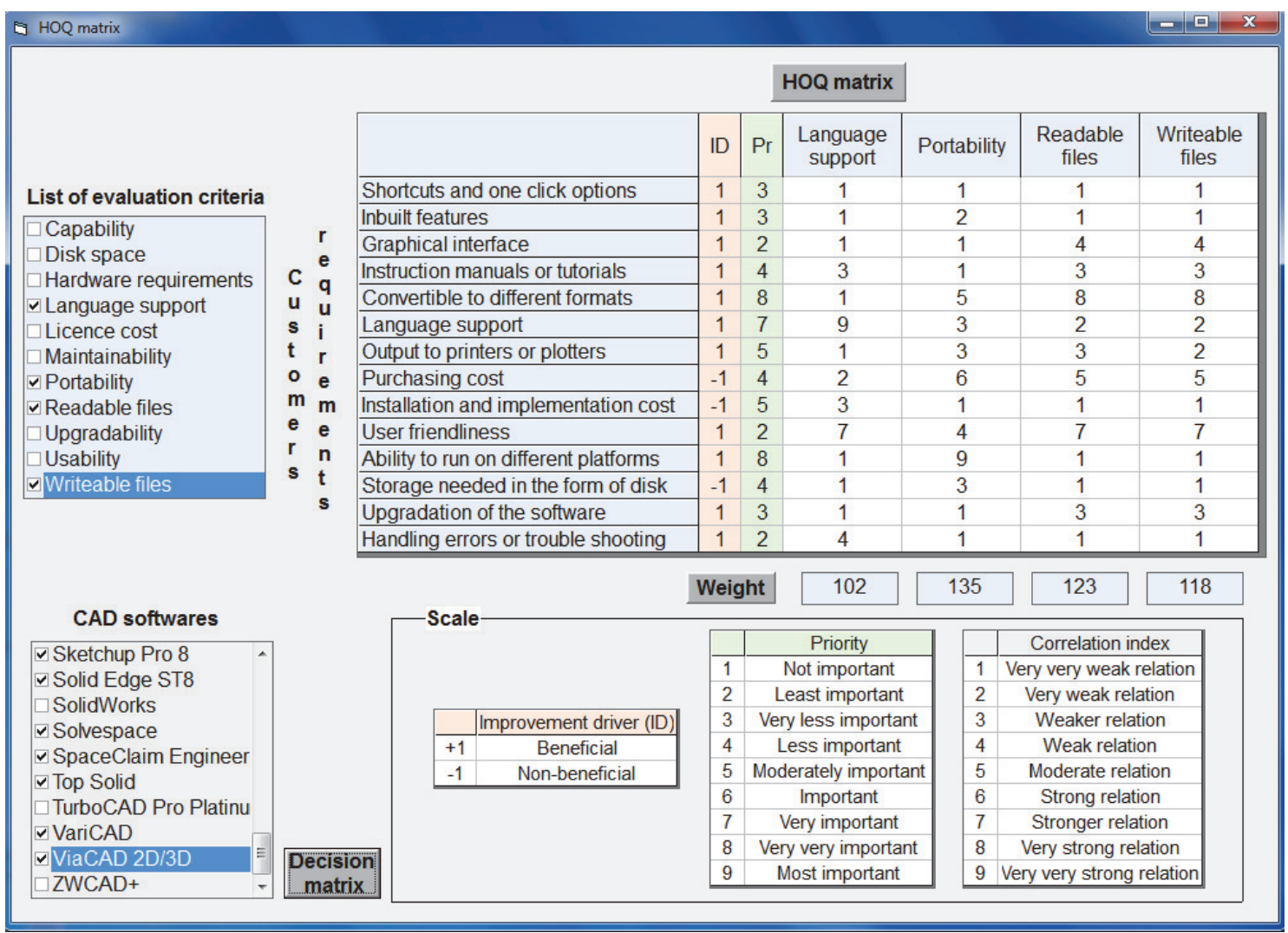

Fig. 5. HOQ matrix for Example 2

Fig. 6 demonstrates the related decision matrix along with the performance scores and ranks for the ten CAD software options, which are obtained on pressing of 'Decision matrix' functional key. Here, SpaceClaim Engineer emerges out as the most appropriate CAD software. It integrates a flexible design environment with a simple graphical user interface. SpaceClaim Engineer enables the end user to create, edit and repair part geometry without worrying about the underlying technology. Moreover, it can work straightforwardly with imported data. Besides, it also encourages real time design evaluation in addition of being more effective in collaboration and communication. Thus, it can be concluded that the result elicited from the implementation of QFD-based model, i.e. SpaceClaim Engineer as the most suitable CAD software package based on the considered criteria, is truly justified. Additionally, SALOME is identified as the least efficient CAD software package owing to its poor performance on 'Language support' and 'Portability' criteria.

\begin{tabular}{|c|c|c|c|c|c|c|c|c|}
\hline \multicolumn{7}{|l|}{ Decision matrix } & \multirow{2}{*}{\multicolumn{2}{|c|}{ Specifications }} \\
\hline \multirow{2}{*}{\multicolumn{7}{|c|}{ Decision matrix }} & & \\
\hline & & & & & & & \multirow{2}{*}{$\begin{array}{l}\text { CAD software : } \\
\text { Developer : } \\
\text { Operating platform : } \\
\text { Processor: }\end{array}$} & \multirow{2}{*}{$\begin{array}{l}\text { SpaceClaim Engineer } \\
\text { SpaceClaim Corporation, USA } \\
\text { Windows } 8 \\
\text { Pentium } 84 \text { and above, } 2 \mathrm{GHz}\end{array}$} \\
\hline & $\mathrm{C} 1$ & $\mathrm{C} 2$ & $\mathrm{C} 3$ & $\mathrm{C} 4$ & Score & Rank & & \\
\hline Caddie & 1 & 1 & 6 & 8 & 48.13 & 9 & \multirow{11}{*}{$\begin{array}{l}\text { Disk space : } \\
\text { RAM : } \\
\text { Readable files : } \\
\text { Writeable files : } \\
\text { Language support: } \\
\text { Procurement cost : } \\
\text { Installation : } \\
\text { Training: } \\
\text { Maintenance : } \\
\text { Upgradation : } \\
\text { Features : }\end{array}$} & \multirow{2}{*}{$\begin{array}{l}2 \mathrm{~GB} \\
2 \mathrm{~GB}\end{array}$} \\
\hline CorelCAD & 12 & 3 & 6 & 6 & 228.33 & 4 & & \\
\hline SALOME & 1 & 1 & 5 & 5 & 23.6 & 10 & & 21 \\
\hline Sketchup Pro 8 & 11 & 4 & 8 & 6 & 277.73 & 3 & & \multirow{3}{*}{$\begin{array}{l}21 \\
\text { en, de, zh, fr, ja, it, es, ko, pl, cs, pt } \\
2445 \text { USD }\end{array}$} \\
\hline Solid Edge ST8 & 9 & 2 & 11 & 1 & 160.18 & 6 & & \\
\hline Solvespace & 1 & 3 & 7 & 7 & 139.07 & 7 & & \\
\hline SpaceClaim Engineer & 11 & 1 & 21 & 21 & 320.06 & 1 & & Not available \\
\hline Top Solid & 3 & 3 & 23 & 14 & 308.25 & 2 & & Not available \\
\hline VariCAD & 6 & 2 & 5 & 6 & 120.86 & 8 & & Complex \\
\hline ViaCAD 2D/3D & 1 & 3 & 17 & 1 & 172 & 5 & & Capable \\
\hline & & & & & & & & $\begin{array}{l}\text { Surface skinning } \\
\text { Shrink wrap }\end{array}$ \\
\hline
\end{tabular}

Fig. 6. Decision matrix for Example 2 


\section{Conclusions}

Today, organizations need to make fast decisions in order to be competent to handle huge amount of extrinsic data, and rejoinder to vibrant and dynamic worldwide markets owing to an increase in global competition and shorter product life cycle. CAD software packages have transformed the way how the manufacturing industries design and produce parts. It provides the flexibility to draft and design in a digital landscape that was earlier carried out manually. In addition, CAD software facilitates faster, superior and uncomplicated development of products. It is acknowledged that there is a wide range of CAD software options available in the market with respect to varying functionalities and features. Moreover, management of an enterprise needs to consider various important factors, which are often conflicting in nature while selecting a CAD software package in order to ensure its effectiveness to meet all the requirements of the customer or end-user. Although, there are few published research papers on the implementation of knowledge-based systems for selection of CAD software, none of them has explored the scope of identifying an appropriate CAD package from an exhaustive list of alternatives available in the market. Therefore, in this paper, a QFD-based software prototype is designed and developed in Visual BASIC 6.0 for solving CAD software selection problems. It is supported by a comprehensive database for CAD software packages containing information on their various technical specifications. The implementation of this system in present day manufacturing environment would minimize human interference while requiring no profound technical knowledge regarding CAD software's functionality, capability, economy and applicability. It signifies that the developed QFD-based software prototype would reduce human error involved in the conventional selection procedure. Presence of a large assortment of CAD software alternatives from various developers into the database demonstrates the developed systems' flexibility and usability. Application of this QFD-based model would also result in cost reduction through decrease in manpower requirement, enhanced workforce efficiency and efficient exploitation of information. Moreover, the results elicited from the implementation of this model exactly corroborate with those as actually being practiced in real time manufacturing environment for a specific set of functionalities.

\section{References}

Akao, Y. (1990). Quality function deployment. Cambridge, MA: Productivity Press.

Ayağ, Z. \& Özdemİr, R.G. (2007). An intelligent approach to ERP software selection through fuzzy ANP. International Journal of Production Research, 45(10), 2169-2194.

Azadeh, A., Shirkouhi, S.N. \& Rezaie, K. (2010). A robust decision-making methodology for evaluation and selection of simulation software package. International Journal of Advanced Manufacturing Technology, 47(1), 381-393.

Cochran, J.K. \& Chen, H-N. (2005). Fuzzy multi-criteria selection of object-oriented simulation software for production system analysis. Computers \& Operations Research, 32(1), 153-168.

Hou, J. (2010). A model for software selection with fuzzy linguistic information. Journal of Convergence Information Technology, 5(10), 188-193.

Jadhav, A.S. \& Sonar, R.M. (2009). Evaluating and selecting software packages: A review. Information and Software Technology, 51(3), 555-563.

Jadhav, A.S. \& Sonar, R.M. (2011). Framework for evaluation and selection of the software packages: A hybrid knowledge based system approach. The Journal of Systems and Software, 84(8), 13941407.

Kannan, G. \& Vinay, V.P. (2008). Multi-criteria decision making for the selection of CAD/CAM system. International Journal on Interactive Design and Manufacturing, 2(3), 151-159.

Karaarslan, N. \& Gundogar, E. (2009). An application for modular capability-based ERP software selection using AHP method. International Journal of Advanced Manufacturing Technology, 42(9), 1025-1033.

Liberatore, M.J. \& Pollack-Johnson, B. (2003). Factors influencing the usage and selection of project management software. IEEE transactions on Engineering Management, 50(2), 164-174. 
Misra, S.K. \& Ray, A. (2012). Comparative study on different multi-criteria decision making tools in software project selection scenario. International Journal of Advanced Research in Computer Science, 3(4), 172-178.

Mulebeke, J.A.W. \& Zheng, L. (2006). Analytical network process for software selection in product development: A case study. Journal of Engineering and Technology Management, 23(4), 337-352.

Perera, H.S.C. \& Costa, W.K.R. (2008). Analytic hierarchy process for selection of ERP software for manufacturing. The Journal of Business Perspective, 12(4), 1-11.

Rao, R.V. \& Rajesh, T.S. (2009). Software selection in manufacturing industries using a fuzzy multiple criteria decision making method, PROMETHEE. Intelligent Information Management, 1(3), 159165.

Şen, C.G. \& Baraçlı, H. (2010). Fuzzy quality function deployment based methodology for acquiring enterprise software selection requirements. Expert Systems with Applications, 37(4), 3415-3426.

Şen, C.G., Baraçl1, H., Şen, S. \& Baslıgil, H. (2009). An integrated decision support system dealing with qualitative and quantitative objectives for enterprise software selection. Expert Systems with Applications, 36(3), 5272-5283.

Yazgan, H.R., Boran, S. \& Goztepe, K. (2009). An ERP software selection process with using artificial neural network based on analytic network process approach. Expert Systems with Applications, 36(5), 9214-9222.

Zakria, G., Guan, Z., Riaz, Y., Jahanzaib, M. \& Khan, A. (2010). Selecting and prioritizing key factors for CAD/CAM software in small-and medium-sized enterprises using AHP. Frontiers of Mechanical Engineering, 5(2), 157-164.

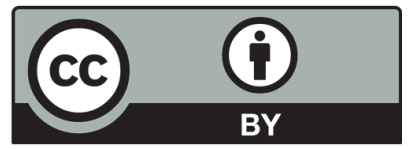

(C) 2016 by the authors; licensee Growing Science, Canada. This article is an open access article distributed under the terms and conditions of the Creative Commons Attribution (CC-BY) license (http://creativecommons.org/licenses/by/4.0/). 